\title{
Anthurium affine schott (araceae): análise anatômica e histoquímica para identificação de estruturas secretoras
}

Anthurium affine Schott é uma Araceae endêmica do Brasil e nativa da Mata Atlântica. Suas folhas e flores são empregadas para o tratamento de diabetes, doenças cardíacas e circulatórias e infecções uterinas na medicina popular por possuir compostos como flavonóides, taninos, alcalóides e saponinas, além de seu uso ornamental devido à beleza de suas folhas e inflorescência. O presente estudo teve por objetivo descrever anatômica e histoquímicamente os órgãos vegetativos de A. affine, visando à identificação das estruturas e melhor compreensão da organização interna da espécie. Para isto, foram feitas secções transversais dos órgãos vegetativos e paradérmicas da folha, coradas com Safranina e Azul de Alcian. Para histoquímica, utilizou-se Lugol, Cloreto férrico e Sudan Black, na identificação de amido, compostos fenólicos e lipídios, respectivamente. Notou-se na raiz, caule e folha a presença de cristais de oxalato de cálcio na forma de drusas, bem como de parênquima amilífero, que se concentram na região próxima aos feixes colaterais. Na raiz observou-se a presença de cavidades secretoras, as folhas são isobilaterais e hipoestomáticas. Observou-se ainda, cavidades secretoras, relacionadas ao cilindro vascular estruturas que tem função de secreção de substâncias, possivelmente as responsáveis pela aplicação da espécie para fins medicinais.

Palavras-chave: Anthurium; Fitoquímica; Anatomia vegetal.

\section{Anthurium affine schott (araceae): anatomical and histochemical analysis for the identification of secretory structures}

\begin{abstract}
Anthurium affine Schott is an endemic Araceae from Brazil and native to the Atlantic Forest. Its leaves and flowers are used for the treatment of diabetes, heart and circulatory diseases and uterine infections in folk medicine because it has compounds such as flavonoids, tannins, alkaloids and saponins, besides its ornamental use due to the beauty of its leaves and inflorescence. This study aimed to analyze anatomically and histochemically the vegetative organs of A. affine, aiming to identify the anatomical structures that produce produce and be related and the production and/or storage of compounds with pharmaceutical properties. For this, transverse sections of the vegetative and leaf paradermic organs were made and stained with Safranina and Alcian Blue. For histochemistry, Lugol, Ferric chloride and Sudan Black were used to identify starch, phenolic compounds and lipids, respectively. The presence of calcium oxalate crystals in the form of drusen, as well as the starch parenchyma, were found in the root, stem and leaf, which are concentrated in the region near the collateral bundles. In the root the presence of secretory cavities was observed, the leaves are isobilateral with stomata only on the abaxial surface. It was also observed, secretory cavities, related to the vascular cylinder structures that have secretion function of substances, possibly those responsible for the application of the species for medicinal purposes.
\end{abstract}

Keywords: Anthurium; Phytochemistry; Plant anatomy

\section{Topic: Botânica Agrícola}

Reviewed anonymously in the process of blind peer.
Received: 05/02/2020

Approved: 01/03/2020
Émile Rocha de Lima (iD

Universidade Federal do Rio Grande do Norte, Brasil http://lattes.cnpq.br/9658828504533374 http://orcid.org/0000-0002-8596-1403 emilerochinha@gmail.com

Raimunda Adlany Dias da Silva

Universidade Federal do Rio Grande do Norte, Brasil http://lattes.cnpq.br/1816809780487274

http://orcid.org/0000-0002-3600-6186 adlanydias@gmail.com

\section{Gabrielle Macedo Pereira (it)}

Universidade Federal do Rio Grande do Norte, Brasil http://lattes.cnpq.br/7975202296724439

http://orcid.org/0000-0002-6638-2035

gabrielle.macp@gmail.com

\author{
Fernanda Gondim Lambert Moreira (iD) \\ Universidade Federal do Rio Grande do Norte, Brasil \\ http://lattes.cnpq.br/6133580535985212 \\ http://orcid.org/0000-0003-1555-8093 \\ fernandaglmoreira@hotmail.com \\ Allyne do Nascimento Eufrásio Silva (iD \\ Universidade Federal do Rio Grande do Norte, Brasil \\ http://lattes.cnpq.br/0550309219697361 \\ http://orcid.org/0000-0001-8575-559X \\ allyne_16eufrasio@hotmail.com \\ Juliana Espada Lichston \\ Universidade Federal do Rio Grande do Norte, Brasil \\ http://lattes.cnpq.br/0727435909982933 \\ http://orcid.org/0000-0002-4042-4524 \\ j.lichston@gmail.com
}

\section{Referencing this:}

LIMA, É. R.; SILVA, R. A. D.; PEREIRA, G. M.; MOREIRA, F. G. L.; SILVA, A. N. E.; LICHSTON, J. E.. Anthurium affine schott (araceae): análise anatômica e histoquímica para identificação de estruturas secretoras Revista Ibero Americana de Ciências Ambientais, v.11, n.2, p.92-98, 2020. DOI: http://doi.org/10.6008/CBPC2179-6858.2020.002.0011 


\section{INTRODUÇÃO}

A família Araceae faz parte das monocotiledôneas herbáceas, que inclui 118 gêneros e cerca de 3.437 espécies, no Brasil existem 691 espécies catalogadas até o ano de 2015 (COELHO et al., 2015), com hábitos terrícolas, rupícola, epífita, hemiepífita e hemiparasita (COELHO et al., 2015; MAYO et al., 1997). Apresenta ampla distribuição, no entanto, têm maior ocorrência em região dos trópicos úmidos, pois não suporta condições extremas, ocorrendo de forma mais numerosa nas Américas, no Sudeste Asiático, na África, no Arquipélago Malaio, na Eurásia e nas Ilhas Seychelles (MAYO et al., 1997; TAKAHASHI et al., 2009).

As espécies da família apresentam amplo potencial econômico, sendo exploradas como ornamentais e alimentícias (MAYO et al., 1997). Algumas são popularmente citadas por sua toxicidade, tais como Dieffenbachia picta e Mostera deliciosa, amplamente cultivadas no Brasil (SIMÕES et al., 2010), outras por seu potencial medicinal a Philodendron scabrum K. Krause e Montrichardia linifera (Arruda) Schott (OTTOBELLI et al., 2011; AMARANTE et al., 2011).

A principal característica morfológica externa compartilhada entre as espécies da família é uma inflorescência em forma de espiga de pequenas flores sobre um eixo denominado espádice (JUDD et al., 2009). Há geralmente a presença de cristais de oxalato de cálcio (na forma de ráfides ou drusas), e estruturas secretoras, incluindo canais de resina, laticíferos, nectários extraflorais e cavidades de mucilagem onde há produção de óleos essenciais e alcaloides utilizados na indústria farmacêutica (MAYO et al., 1997).

O gênero Anthurium é o maior da família, incluindo 950 espécies distribuídas na região Neotropical. No Brasil há cerca de 131 espécies (COELHO et al., 2015) popularmente denominadas de Antúrio. São em sua maioria epífitas, porém podem ser ocasionalmente hemiepífitas, terrestres, litófitas, helófitas ou reófitas (MAYO et al., 1997). O Anthurium affine Schott é uma espécie endêmica do Brasil, nativa da mata atlântica, apresentando ampla importância na preservação e fixação das dunas (COELHO et al., 2015; FREIRE, 1990). A espécie apresenta antocianinas (cianidina e pelargonidina) responsáveis pela coloração avermelhada de seus frutos. Além do potencial ornamental o $A$. affine apresenta flavonóides, taninos, alcalóides e saponinas, responsáveis por tornar a espécie aplicável na medicina (LUNA et al., 2017).

É utilizada para o tratamento de diabetes, através da maceração de suas flores, problemas cardíacos e doenças circulatórias, por meio de infusão de suas folhas, atuam ainda, no combate a infecções uterinas, é utilizada como vinho medicinal (AGRA et al., 2008; ALVES et al., 2013), em animais é usada no tratamento de mí́ase (SILVA et al., 2014). Mediante o exposto, o presente estudo objetivou analisar anatômica e histoquimicamente os órgãos vegetativos de $A$. affine, visando a identificação das estruturas e melhor compreensão da organização interna da espécie.

\section{MATERIAIS E MÉTODOS}

A coleta do material vegetal se deu de forma aleatória, nas dependências do campus da Universidade Federal do Rio Grande do Norte - UFRN, localizada em Natal/RN. Foram coletadas amostras de raiz, caule e folha, e acondicionado em etanol $70 \%$. As análises morfoanatômicas e histoquímicas foram realizadas no 
Laboratório de Investigação de Matrizes Vegetais Energéticas - LIMVE na UFRN. Foram feitas seç̧ões transversais, longitudinais e paradérmicas à mão livre, utilizando lâminas de aço inoxidável, para confecção de lâminas semipermanentes. Para as identificações teciduais, os cortes foram submetidos à coloração com os reagentes Azul de Alcian 1\% e Safranina 1\%, em sequência, montados em glicerina 50\% seguindo a recomendação de Kraus et al. (1997). Para as análises histoquímicas dos órgãos, as secções histológicas foram submetidas aos reagentes lugol 5\%, Sudan Black 0,07\% e Cloreto férrico, a fim de identificar de amido, lipídios e compostos fenólicos, respectivamente (KRAUS et al., 1997).

\section{RESULTADOS E DISCUSSÃO}

Na raiz de Anthurium affine, observou-se velame pluriestratificado exteriormente à epiderme, que é unisseriada com células tabulares (Figuras 1A, B). O velame pode ser encontrado em raízes aéreas de algumas orquidáceas, aráceas epífitas e de outras monocotiledôneas terrestres. É uma epiderme múltipla constituída de células mortas com paredes espessadas que dá proteção mecânica e reduz a perda de água, em A. affine, e em algumas outras espécies do gênero, a epiderme múltipla, ou velame, é formada por células mortas com espessamentos fibrosos (MAYO et al., 1997). Foi caracterizado o velame em Araceae como sendo uma protoderme.

A epiderme é seguida então por 14 a 17 camadas de células de parênquima cortical. Idioblastos contendo cristais de oxalato de cálcio na forma de drusas se encontram dispersos por todo o córtex, e sua frequência aumenta conforme se aproximam do cilindro vascular, fazendo-se presentes inclusive na endoderme (Figura 1A). No parênquima do córtex radicular também se observa quantidade expressiva de amiloplastos (Figura 1C). Grãos de amido em Anthurium sp podem estar presentes nas células parenquimáticas corticais, próximas aos feixes vasculares e no colênquima.

Polos de floema intercalam-se com os arcos do xilema primário no cilindro vascular, no qual também se encontram cavidades delimitadas por uma camada de células com lúmen volumoso (Figura 1D). A presença de canais de mucilagem e cavidades é limitada na família Araceae, ocorrendo em poucos gêneros, como em Anthurium, tendo uma epiderme distinta, formada por células pequenas com citoplasma amplo (MAYO et al., 1997), sendo possível local de reserva e secreção de metabólitos secundários.

Em vista frontal das folhas, as paredes das células epidérmicas variam de retas a levemente curvas (Figura 2A). Estômatos tetracíticos são encontrados apenas na face abaxial da folha, e estão distribuídos de maneira aleatória (Figura 2B). Corroborando, em parte, que ao estudarem nove espécies de Anthurium, encontraram estômatos distribuídos de maneira aleatória na face abaxial, como observado no presente estudo, porém observaram também na face adaxial, com concentração apenas na nervura central.

Nas secções transversais da folha possibilitou a verificação de epiderme foliar unisseriada, com cutícula delgada em toda sua extensão (Figura 2C). Foram encontradas poucas camadas de parênquima paliçádico próximos à superfície adaxial da folha, sendo por isso dorsiventral, e 10-14 camadas de parênquima lacunoso, preenchendo quase todo o restante do mesofilo. Em A. affine, os dois tipos de parênquima não têm uma distinção muito clara, característica observada também em outras espécies do 
gênero.

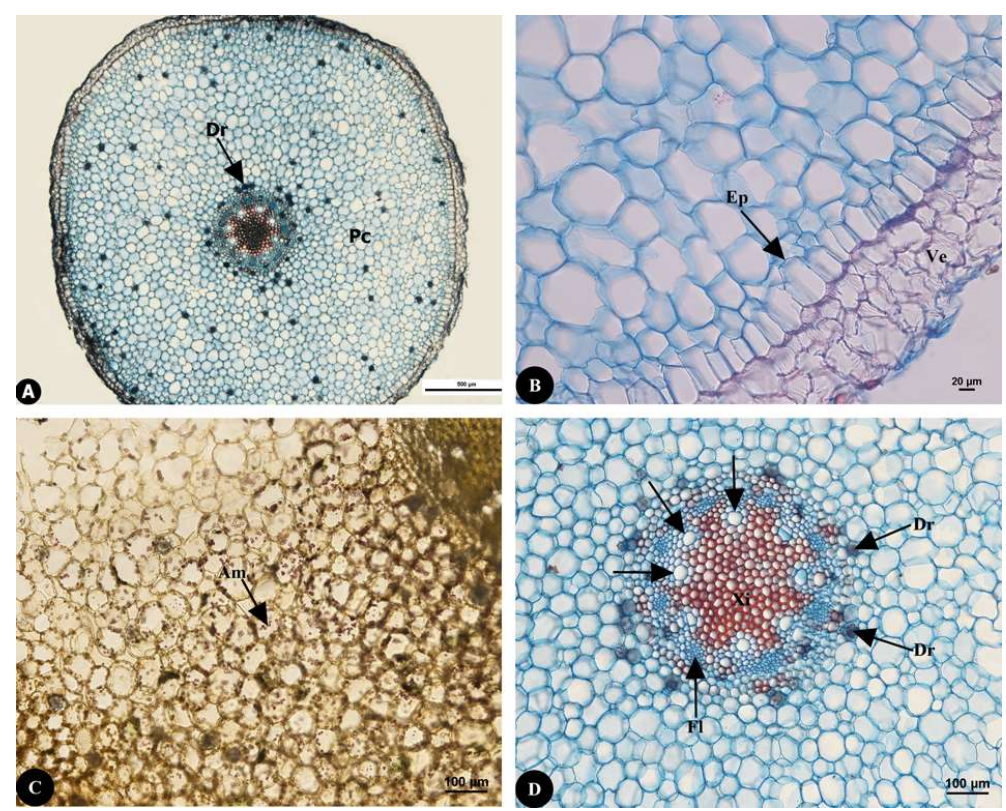

Figura 1: Secções transversais da raiz de Anthurium affine: A - Visão geral da disposição tecidual na raiz evidenciando o parênquima e as drusas; B - Detalhe das células epidérmicas (Ep) e do velame (Ve); C - Parênquima amilífero (Am);

$D$ - Cilindro vascular da raiz, evidenciando drusas (Dr) e cavidades secretoras (setas).

As células parenquimáticas do mesofilo possuem amiloplastos e drusas, que estão distribuídos de maneira aleatória em todo o mesofilo e na endoderme dos feixes vasculares (Figuras 2D, F). Na nervura central, camadas de colênquima situam-se logo abaixo da epiderme nas duas faces da folha, seguido de parênquima amilífero, onde estão imersos feixes vasculares colaterais. Células de esclerênquima estão associadas ao floema dos feixes vasculares (Figura 2E).

Os amiloplastos e as drusas no parênquima, assim como visto na raiz, aumentam sua frequência conforma se aproximam da endoderme dos feixes. A ocorrência dos grãos de amido e dos cristais, próximos aos feixes vasculares, evidenciam a função de armazenamento e produção de energia, visto que os feixes são responsáveis pelo trânsito de substâncias pela planta.

As drusas são pouco comuns em monocotiledôneas, porém, podem ocorrer em tecidos aerenquimatosos em alguns gêneros de Araceae, incluindo Anthurium (PRYCHID et al., 1999). Foi demonstrado que dois ou mais tipos de cristais podem ocorrer simultaneamente em um mesmo órgão em plantas desta família, mas em A. affine, apenas os cristais, do tipo drusa, são observados com maior incidência, no mesófilo, corroborando com o visto por Genua et al. (1985).

Em Anthurium scadens estão ainda presentes tanto nas células do mesofilo quanto nas da epiderme das folhas em outros gêneros da família Araceae. Oliveira et al. (2017) descreveram anatomicamente 30 espécies ornamentais, dentre elas, 23 apresentaram cristais de oxalato de cálcio, incluindo a espécie Anthurium andraeanum apontada como tóxica. Na família Araceae, esses cristais estão relacionados à toxicidade do vegetal (HERNANDEZ et al., 2017) e também a defesa (ZINI et al., 2015). Os diferentes tipos de cristais podem ser relevantes ainda para caracterização taxonômica da família (PRYCHID et al., 1999). 

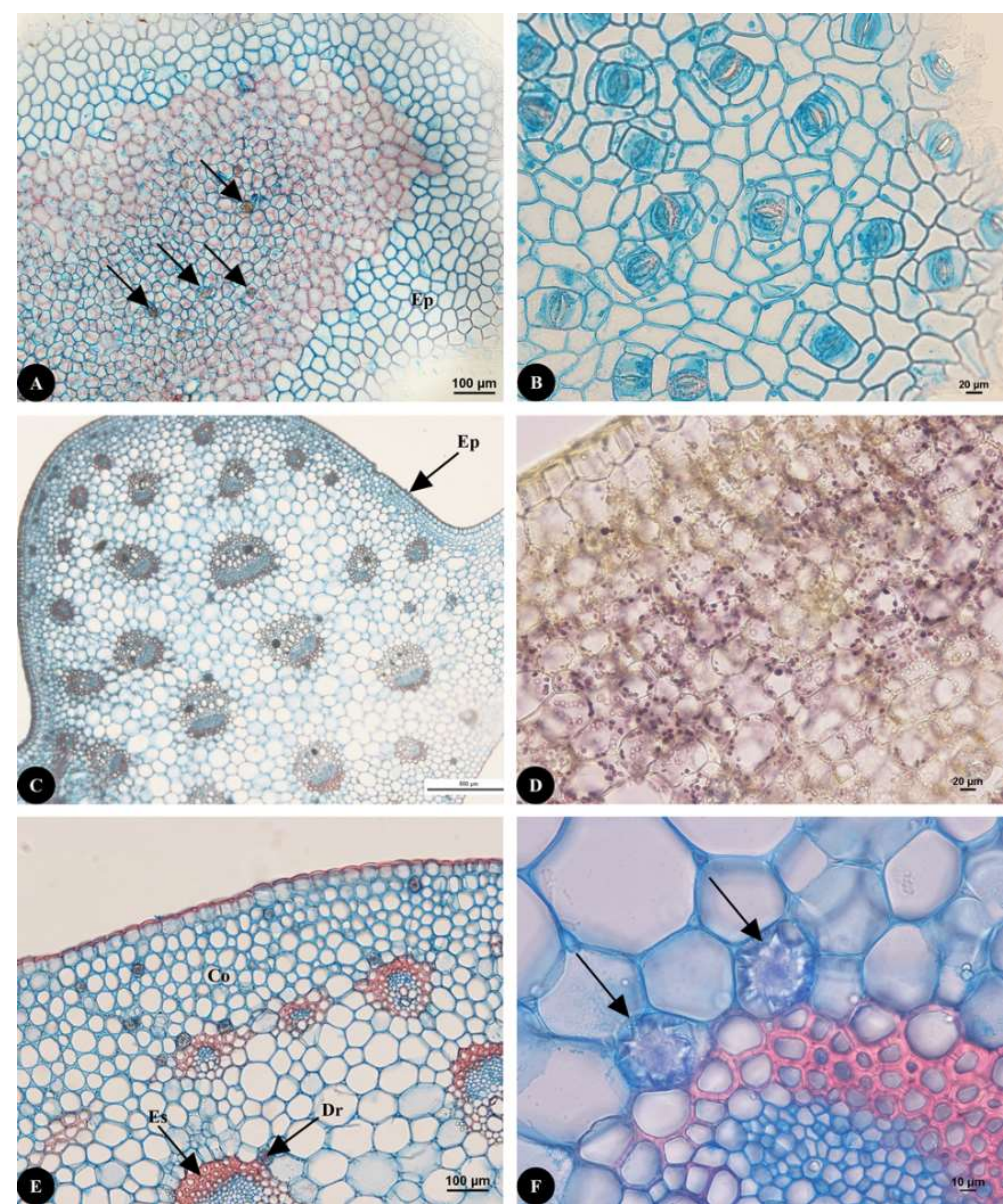

Figura 2: Secções paradérmicas (A-B) e transversais (C-F) das folhas de $A$. affine. A - Vista frontal das células epidérmicas evidenciando drusas (setas); B - Detalhes dos estômatos na face abaxial da folha; C - Visão geral da nervura central repleta de feixes vasculares; D - Mesofilo evidenciando amiloplastos; E - Disposição do colênquima (Co) e dos feixes vasculares rodeados por esclerênquima (Es) e drusas (Dr); F - Detalhes das drusas próximas ao feixe vascular.

O caule de $A$. affine, é delimitado por uma epiderme unisseriada com células tabulares, seguida por poucas camadas de colênquima e por parênquima de preenchimento. Os feixes vasculares dispersos no parênquima, padrão típico de monocotiledôneas (EVERT et al., 2018), são do tipo colateral (Figura 3A) e possuem numerosas drusas em seu entorno, muito semelhantes ao observado nas folhas, conforme evidenciado em cortes longitudinais do caule (Figura 3B).
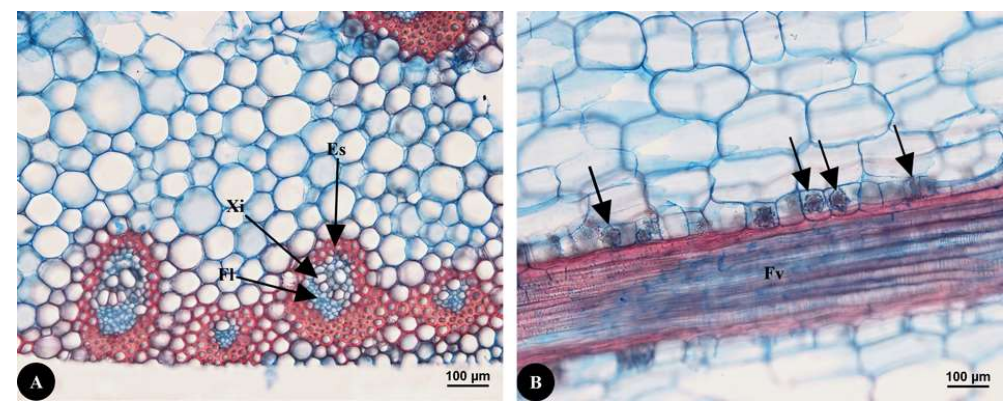

Figura 3: Visão transversal (A) e longitudinal (B) do caule. A - Organização das células nos feixes vasculares, sendo o xilema (Xi) e floema (FI) colateriais; B - Disposição das drusas (setas) ao longo dos feixes vasculares (Fv).

No parênquima caulinar também são encontrados amiloplastos, porém estes estão em menor quantidade quando comparado ao observado para a raiz e folha. A espécie apresentou resultado negativo ao teste de Sudan III e Cloreto Férrico, à medida que não reagiu aos indicadores. Possivelmente os canais 
secretores em $A$. affine estão relacionados ao transporte de substâncias e não ao armazenamento das mesmas.

\section{CONCLUSÕES}

A caracterização anatômica do A. affine possibilita a compreensão da possível relação entre as estruturas anatômicas com o potencial tóxico e o farmacológico, quando se observa a presença de drusas e canais secretores próximos ao cilindro vascular. A presença dos canais e, consequentemente de possíveis substâncias transportadas, pode estar relacionada ao uso da raiz da espécie pela medicina popular, também ao potencial tóxico compartilhado por algumas das espécies da família. Não se observou compostos de caráter lipídicos nem tampouco fenólicos.

\section{REFERÊNCIAS}

AGRA, M. F.; SILVA, K. N.; BASÍLIO I. J. L. D.; FREITAS, P. F.; BARBOSA-FILHO, J. M.. Survey of medicinal plants used in the region Northeast of Brazil. Revista Brasileira de Farmacognosia, v.18, n.3, p.472-508, 2008. DOI: http://doi.org/10.1590/S0102-695X2008000300023

ALVES, G. S. P.; POVH, J. A.. Estudo etnobotânico de plantas medicinais na comunidade de Santa Rita, Ituiutaba - MG. Biotemas, v.26, n.3, p.231-242, 2013. DOI: http://doi.org/10.5007/2175-7925.2013v26n3p231

AMARANTE, C. B.; MÜLLER, A. H.; MÜLLER, R. C. S.; OLIVEIRA, D. J.; LINS, A. L. F. A.; PRADO, A. F.; DOLABELA, M. F.. Estudo farmacognóstico, fitoquímico e citotóxico do extrato etanólico e frações obtidos do caule de Montrichardia linifera (Arruda) Schott (Araceae). Revista Brasileira de Farmácia, v.92, n2, p.60-65, 2011.

COELHO, M. A. N.; SOARES, M. L.; CALAZANS, L. S. B.; GONÇALVES, E. G.; ANDRADE, I. M.; PONTES, T. A.; SAKURAGUI, C. M.; TEMPONI, L. G.; BUTURI, C.; MAYO, S.. Araceae in Lista de Espécies da Flora do Brasil. Rio de Janeiro: Jardim Botânico do Rio de Janeiro 2015.

FREIRE, M. S. B.. Levantamento Florístico do Parque Estadual Dunas de Natal. Acta Botânica Brasílica, v.4, n.2, p.41-59, 1990. DOI: $\underline{\text { http://doi.org/10.1590/S0102- }}$ $\underline{33061990000300006}$

GENUA, J. M.; HILLSON, C. J.. The occurrence, type and location of calcium oxalate crystals in the leaves of fourteen species of Araceae. Annals of Botany, v.56, n.3, p.351-361, 1985. DOI:

http://doi.org/10.1093/oxfordjournals.aob.a087021

HARBORNE, J. B.; WILLIAMS, C. A.. Recent Advances in the Chemosystematics of the Monocotyledons. Phytochenristry, v.37, n.1, p.3-18, 1994. DOI: http://doi.org/10.1016/0031$\underline{9422(94) 85004-6}$

HERNANDEZ, E. M. M.; RODRIGUES, R. M. R.; TORRES, T. M.; ZUCOLOTO, A. D.; OLIVEIRA, C. D. R.; EGITO, E. S. T.; FRUCHTENGARTEN, L. V. G.. Manual de toxicologia clínica: orientações para assistência e vigilância das intoxicações agudas. In: MANUAL DE TOXICOLOGIA CLÍNICA: ORIENTAÇÕES PARA ASSISTÊNCIA E VIGILÂNCIA DAS
INTOXICAÇÕES AGUDAS. Anais. 2017. p.465.

JUDD, W. S.; CAMPBELL, C. S.; KELLOGG, E. A.; STEVENS, P. F.; DONOGHUE, M. J.. Sistemática Vegetal: Um Enfoque Filogenético. 3 ed. São Paulo: Artmed, 2009.

KRAUS, J. E.; ARDUIN, M.. Manual básico de métodos em morfologia vegetal. Rio de Janeiro: EDUR, 1997.

MAYO, S. J.; BOGNER, J.; BOYCE, P. C.. The genera of Araceae. London: Royal Botanical Garden, 1997.

LUNA, J. G.; SOUZA, D. M. B.; JIMENEZ, G. C.; NETO, J. S.; NETO, J. E.. Análises fitoquímicas em extrato das folhas de Anthurium affine Schott (milho de urubu). Medicina Veterinária (UFRPE), v.10, n.1-4, p.1-4, 2017.

OLIVEIRA, R. R.; PASIN, L. A. A.. Pereira. Ocorrência de oxalato de cálcio em diferentes espécies vegetais de uso ornamental. Revista de Ciências Ambientais, v.11, n.3, p.4152, 2017. DOI: http://doi.org/10.18316/rca.v11i3.3571

OTTOBELLI, I.. Estudo químico de duas plantas medicinais da amazônia: Philodendron scabrum k. Krause (araceae) e Vatairea guianensis aubl. (fabaceae). Acta Amazônica, v.41, p.393-400, 2011.

PRYCHID, C. J.; RUDALL, P. J.. Calcium oxalate crystals in monocotyledons: a review of their structure and systematics. Annals of botany, v.84, n.6, p.725-739, 1999. DOI: http://doi.org/10.1006/anbo.1999.0975

EVERT, R. F.; EICHHORN, S. E.. Raven Biologia vegetal. 8 ed. Rio de Janeiro: Guanabara Koogan, 2018.

SILVA, F. S.; ALBUQUERQUE, U. P.; JÚNIOR, L. M. C.; SILVA LIMA, A.; NASCIMENTO, A. L. B.; MONTEIRO, J. M.. An ethnopharmacologica lassessment of the use of plants against parasitic diseases in humans and animals. Journal of Ethnopharmacology, v.115, p.1332-1341, 2014. DOI: http://doi.org/10.1016/i.jep.2014.07.036

SIMÕES, C. M. O.; SCHENKEL, E. P.; MELLO, J. C. P.; MENTZ, L. A.; PETROVICK, P. R.. Farmacognosia: da planta ao medicamento. 6 Ed. Porto Alegre: UFRGS, 2010. 
TAKAHASHI, L. S. A.; FARIA, R. T.; TOMBOLATO, A. F. C.;

CUQUEL, F. L.; GROSSI, M. L.. Desenvolvimento de cultivares de antúrio IAC como plantas de vaso no norte do Paraná. Bragantia, v.68, n.3, p.593-600, 2009.
ZINI, A. D. S.; MARTINS, S.; TODERKE, M. L.; TEMPONI, L. G.. Foliar anatomy of Rubiaceae occurring in an urban forest fragment of Atlantic Forest, Paraná State, Brazil. Hoehnea, v.43, n.2, p.173-182, 2015. DOI:

http://doi.org/10.1590/2236-8906-59/2015

A CBPC - Companhia Brasileira de Produção Científica (CNPJ: 11.221.422/0001-03) detém os direitos materiais desta publicação. Os direitos referem-se à publicação do trabalho em qualquer parte do mundo, incluindo os direitos às renovações, expansões e disseminações da contribuição, bem como outros direitos subsidiários. Todos os trabalhos publicados eletronicamente poderão posteriormente ser publicados em coletâneas impressas sob coordenação da Sustenere Publishing, da Companhia Brasileira de Produção Científica e seus parceiros autorizados. Os (as) autores (as) preservam os direitos autorais, mas não têm permissão para a publicação da contribuição em outro meio, impresso ou digital, em português ou em tradução. 